\title{
MAPEAMENTOS ICÔNICOS NA ESTRUTURA INTERNA DOS VERBOS EM LÍNGUA BRASILEIRA DE SINAIS
}

\author{
Michelle Andréa MURTA iD $\boldsymbol{Z}$ \\ Faculdade de Letras - Universidade Federal de Minas Gerais (UFMG) \\ Guilherme LOURENÇO (D) \\ Faculdade de Letras - Universidade Federal de Minas Gerais (UFMG)
}

OPEN ACCESS

EDITORES

- Miguel Oliveira, Jr. (UFAL)

- René Almeida (UFS)

AVALIADORES

- Anderson Silva (UFPI)

- Adeilson Sedrins (UFRPE)

- Danniel Carvalho (UFG)

SOBRE OS AUTORES

- Michelle Andréa Murta Conceptualização, Investigação, Escrita - Rascunho Original.

- Guilherme Lourenço

Conceptualização, Supervisão, Investigação, Escrita - Rascunho Original.

DATAS

- Recebido: 03/08/2021

- Aceito: 08/09/2021

- Publicado: 27/10/2021

COMO CITA

MURTA, Michelle Andrea; LOURENÇO, Guilherme (2021). Mapeamentos icônicos na estrutura interna dos verbos em Língua Brasileira de Sinais. Cadernos de Linguística, v. 2, n. 4 , e450.

\section{RESUMO}

Este trabalho investiga os mapeamentos icônicos presentes na estrutura interna dos verbos na Língua Brasileira de Sinais (Libras). Entendemos iconicidade como uma relação analógica entre forma e significado, de modo que há semelhança ou similaridade entre eles (MEIR; TKACHMAN, 2018). Além da iconicidade, o presente trabalho aborda a estrutura morfofonológica dos verbos em Libras. Adotamos a proposta de Lourenço (2018a, 2018b) e Lourenço e Wilbur (2018) de que há uma simultaneidade de informações visuais, envolvendo cinco estruturas morfofonológicas do item verbal: as expressões não manuais, que compreendem a face superior e a face inferior, e os três parâmetros primários, que compreendem configuração de mão, movimento e locação. A partir dos conceitos de iconicidade e de estrutura morfofonológica interna dos verbos, questionamos se é possível identificar mapeamentos icônicos independentes em cada "camada" de informação visual da estrutura verbal, que chamaremos de slots morfológicos. Argumentaremos que há, sim, mapeamentos icônicos na estrutura morfológica do item verbal e que cada slot morfológico pode codificar relações icônicas entre forma e significado. Além disso, indicamos ser possível estabelecer o grau de iconicidade que um item verbal possui a partir da quantidade de mapeamentos 
icônicos presentes em sua estrutura interna, de modo a construirmos uma escala de iconicidade que leva em consideração a estrutura morfofonológica do item lexical.

\section{ABSTRACT}

This paper investigates iconic mappings within the internal structure of verbs in Brazilian Sign Language (Libras). We understand iconicity as an analogic relation between form and meaning, in which there is resemblance or similarity (MEIR; TKACHMAN, 2018). Other than iconicity, we also investigate the morphophonological structure of the verbs in Libras. Assuming the proposals by Lourenço (2018a, 2018b) and Lourenço and Wilbur (2018), in which they assume that there are simultaneous pieces of visual information, regarding five different morphophonological structures of the verb, to wit: nonmanual markers, including both superior face and inferior face, and the three primary parameters, that are handshape, movement and location. Building on these two concepts - iconicity and internal morphophonological structure of the verb - we investigate whether is possible to identify iconic mappings in each layer, or slots, of visual information of the verb structure. Our claim is that there are, indeed, iconic mappings in the morphological structure of the verb and that each morphological slot can map iconic relations between form and meaning. Additionally, we propose that is possible to determine the degree of iconicity of a given verb item, considering the number of iconic mappings present in its internal structure. This results in an iconicity scale that takes into consideration the morphophonological structure of the lexical item.

\section{PALAVRAS-CHAVE}

Morfofonologia Verbal; Iconicidade; Língua de Sinais; Libras.

\section{KEYWORDS}

Verbal Morphophonology; Iconicity; Sign Language; Libras. 


\section{INTRODUÇÃO}

O presente trabalho visa contribuir para os estudos da Libras, ao investigar os mapeamentos icônicos presentes na estrutura interna dos verbos nessa língua. Nesse sentido, traremos uma discussão sobre a interface entre a morfofonologia verbal e a semântica.

Entendemos iconicidade como uma relação analógica entre forma e significado, de modo que há semelhança ou similaridade entre eles (MEIR; TKACHMAN, 2018). Essa relação é encontrada tanto nas línguas orais quanto nas línguas sinalizadas e Taub (2001, p. 20) afirma que ela está "presente em todos os níveis da estrutura linguística, incluindo a morfologia e a sintaxe, bem como em palavras individuais". "A autora ainda reforça que a iconicidade não se trata de uma "simples" semelhança entre a forma e o significado, mas de "um processo sofisticado no qual os recursos fonéticos permissíveis de uma língua compõem um ‘analógico' de uma imagem associada ao referente”2 (TAUB, 2001, p. 20).

Além da iconicidade, o presente trabalho aborda a estrutura morfofonológica dos verbos em Libras. Adotamos, portanto, a proposta de Lourenço (2018a, 2018b) e Lourenço e Wilbur (2018) de que há uma simultaneidade de informações visuais, envolvendo cinco estruturas morfofonológicas do item verbal, a saber: as expressões não manuais, que compreendem a face superior e a face inferior, e os três parâmetros primários, que compreendem configuração de mão, movimento e locação. Assim, a sobreposição dessas informações visuais em "camadas", que os autores chamam de layering, é o que compõe a estrutura verbal e que é responsável pela marcação morfológica de diferentes aspectos gramaticais, como, por exemplo, concordância e marcação aspectual. Vale salientar que, assim como observado no trabalho de Lourenço, o conceito de morfofonologia que adotamos aqui advém do fato de que, ao se aplicar as operações morfológicas previstas pelo modelo, tem-se mudanças na estrutura fonológica do sinal. Nesse sentido, Lourenço (2018a, 2018b) e Lourenço e Wilbur (2018) oferecem um modelo teórico que prevê qual estrutura fonológica interna do item lexical será alvo de cada uma das operações morfológicas assumidas. Esses morfemas propostos podem codificar diferentes informações lexicais e ou gramaticais, que serão discutidas com mais detalhes na Seção 3.

A partir dos conceitos de iconicidade e de estrutura morfofonológica interna dos verbos, questionamos se é possível identificarmos mapeamentos icônicos independentes em cada "camada" de informação visual da estrutura verbal, que chamaremos de slots morfológicos, e quais os efeitos desses mapeamentos icônicos nos processos

1 [...] present at all levels of linguistic structure, including morphology and syntax as well as individual words.

2 but a sophisticated process in which the allowable phonetic resources of a language are built up into an "analogue" of an image associated with the referent. 
morfológicos verbais. Em específico, analisaremos os verbos ancorados ao corpo e que possuem como localização a cabeça, o tronco ou o braço, seguindo a lista de verbos encontrada em Lourenço (2018a).

Demonstraremos que mapeamentos icônicos podem, sim, ser identificados na estrutura morfológica do item verbal e cada slotmorfológico pode codificar essas relações icônicas entre forma e significado. Além disso, argumentaremos que é possível determinar o grau de iconicidade que um item verbal possui a partir da quantidade de mapeamentos icônicos presentes em sua estrutura interna, de modo a construirmos uma escala de iconicidade que leva em consideração a estrutura morfofonológica do item lexical.

\section{A ICONICIDADE NAS LÍNGUAS DE SINAIS}

Por muito tempo, a tradição linguística considerou - e tem considerado - que o signo linguístico é arbitrário. Essa tradição Saussuriana (SAUSSURE, 1915) tem retirado, em certa medida, o fenômeno da iconicidade do centro das pesquisas sobre a estrutura das línguas naturais. Se, por um lado, entendemos a arbitrariedade como sendo uma ausência de relação ou conexão motivada entre forma e significado, a iconicidade pode ser conceituada como uma relação analógica entre forma e significado, de modo que há semelhança ou similaridade entre eles (MEIR; TKACHMAN, 2018).

Na Figura 1, vemos um sinal da Libras que é considerado arbitrário e outro que é tradicionalmente considerado como um sinal icônico. O verbo TRABALHAR pode ser considerado um item lexical arbitrário, uma vez que não apresenta nenhuma relação de semelhança entre sua forma e seu significado. Por outro lado, o verbo CORRER é tido como um verbo icônico, já que podemos identificar uma relação de semelhança entre a forma do item e o seu significado. A forma do sinal é, portanto, análoga a seu significado.
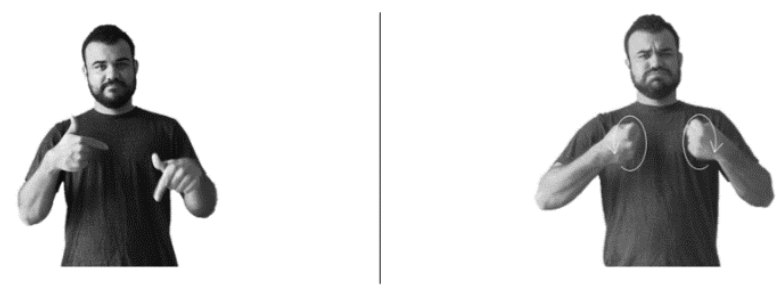

Figura 1. À esquerda, o verbo TRABALHAR, considerado um sinal arbitrário e, à direita, o verbo cORRER, considerado um sinal icônico.

Nas línguas orais, a iconicidade tem sido identificada em diferentes níveis de análise, que vão desde a morfologia e o léxico (WAUGH, 1994), passando pela estrutura da sentença (HAIMAN, 1980) e até mesmo pela prosódia (SHINTEL et al, 2006). Já nas línguas de sinais, a iconicidade tem sido mais frequentemente investigada, pelo fato de que as línguas 
sinalizadas parecem ser mais capazes de codificar e mapear relações de analogia entre forma e significado, devido à modalidade visual-manual desses sistemas de língua. Brentari (2019) vai além e diz que "a habilidade de se preservar a iconicidade parece ser uma vantagem das línguas de sinais. As línguas orais são um pouco 'deficientes de iconicidade'” (BRENTARI, 2019, p. 76). Sobre as possibilidades de se estabelecer relações icônicas entre forma e significado, Aranoff, Meir e Sandler (2005) afirmam que as línguas de sinais têm a capacidade de representar conceitos como fonte, alvo, tema, caminho e tamanho, de maneira motivada, de maneira mais produtiva do que as línguas orais.

Taub (2001, cap. 3) explica também que a iconicidade não é uma relação objetiva entre forma e significado, e sim uma relação entre nossos modelos mentais da imagem e da referência. Em outras palavras, a iconicidade não é uma questão de semelhança direta entre forma e significado, mas um processo em que recursos fonéticos próprios da gramática de uma determinada língua são utilizados para codificar essa relação entre a imagem e o referente. Nesse sentido, é preciso diferenciarmos iconicidade de transparência.

Se, por um lado, temos que a iconicidade é uma relação de analogia entre forma e significado, o conceito de transparência faz referência à capacidade de um indivíduo de inferir o significado de um item linguístico apenas a partir de sua forma (KLIMA; BELLUGI, 1979). Diferentes pesquisadores já investigaram se sinais icônicos de uma determinada língua de sinais são também transparentes para indivíduos que não conhecem essa língua e sua estrutura linguística. Esses trabalhos têm demonstrado que mesmo sinais altamente icônicos não são transparentes, de modo que uma pessoa que não conhece a língua de sinais em questão não consegue identificar corretamente seu significado (HOEMANN, 1975; KLIMA; BELLUGI, 1979; GROSSO, 1993; ORTEGA et al, 2017; SEVCIKOVA SEHYR; EMMOREY, 2019; inter alia).

Ortega et a/ (2017) apresenta ainda uma discussão interessante sobre a relação entre iconicidade e transparência. Segundo os autores, os participantes da pesquisa realizada por eles - ouvintes que desconheciam a Língua de Sinais Holandesa (NGT, Nederlandse Gebarentaa) - conseguiam identificar o significado de sinais icônicos em maior proporção quando esses sinais eram semelhantes a gestos utilizados por esses próprios sujeitos. Isso demonstra que a experiência gestual do indivíduo pode influenciar em sua percepção sobre a iconicidade e a transparência de um item lexical.

A partir do entendimento de que iconicidade não significa transparência, Sevcikova e Emmorey (2019, p. 210) afirmam que:

A habilidade de se depreender uma relação icônica entre a forma e o significado depende da experiência linguística, cultural e sensorial (auditiva, por exemplo) do indivíduo e pode ser ainda mediada por propriedades específicas do próprio sinal ou da palavra. A experiência linguística advém do conhecimento e do uso que o indivíduo faz do sistema linguístico em 
questão, que podem moldar a construção de relações entre forma e significado de um determinado sinal ou palavra. ${ }^{3}$

Em suma, chamamos a atenção para a observação feita na literatura de que a iconicidade é uma relação mediada pela estrutura do sistema gramatical da língua em questão. Passaremos, então, a discutir o modelo de mapeamento icônico proposto por Taub (2001).

\subsection{O MODELO DE CONSTRUÇÃO ANALÓGICA DA ICONICIDADE LINGUÍSTICA}

Com o objetivo de explicar como elementos icônicos surgem nas línguas, Taub (2001, cap. 4) propõe o Modelo de Construção Analógica da Iconicidade Linguística. Segundo a autora, essa proposta teórica tem o objetivo de oferecer ferramentas para se descrever, modelar e analisar os itens icônicos de uma determinada língua (TAUB, 2001, p. 43).

O Modelo de Taub parte do princípio de que há mapeamentos do significado para a forma do item icônico e de que esse mapeamento deve sempre preservar a estrutura de analogia entre a forma e o seu significado. Em outras palavras, o modelo propõe que os materiais fonéticos da língua (sejam eles sons, movimentos ou formas) devem ser capazes, em um item icônico, de preservar a relação de analogia entre a forma e o significado do item. Ainda segundo a autora, o modelo é aplicável tanto para línguas sinalizadas quanto para línguas orais.

Taub (2001) propõe que esse processo de construção analógica da iconicidade envolve três processos: (1) seleção imagética, (2) esquematização; e (3) codificação. Assim, na criação de um item icônico, uma imagem a ser representada é selecionada, modificada ou esquematizada de modo a ser possível torná-la representável pela língua e, em seguida, são selecionadas formas presentes na estrutura da língua que são capazes de mostrar ou de codificar essa(s) determinada(s) imagem(ns) (TAUB, 2001, p. 44). Esses processos são ilustrados na figura a seguir, que mostra o processo de criação do sinal TREE (árvore) em ASL (Língua de Sinais Americana).

3 The ability to apprehend the iconic relationship between form and meaning depends on one's linguistic, cultural, and sensory (e.g., auditory) experience and might further be mediated by properties of the signs or words themselves. Linguistic experience arises from the individual's knowledge and use of the relevant language system which could shape the construal of the link between form and meaning in a given sign or word. 


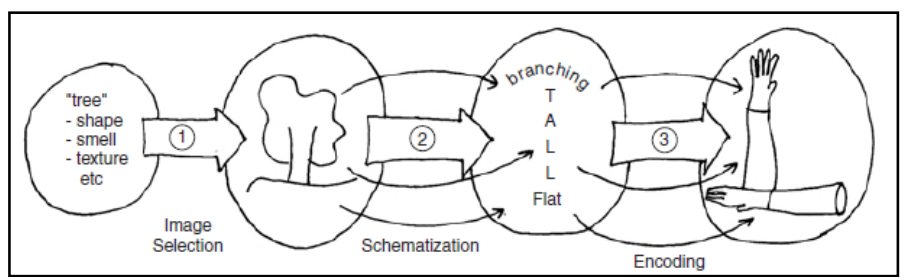

Figura 2. Processo de construção analógica do sinal icônico TREE em ASL. Fonte: Taub (2001, p. 44).

Passaremos agora a discutir cada um desses processos, segundo Taub (2001). Para uma discussão mais detalhada, remetemos o leitor ao Capítulo 4 de Taub (2001).

Ao falar sobre seleção imagética, é preciso lembrar que o processo de construção analógica começa com um conceito que necessita de representação linguística. Isso quer dizer que a representação fará referência a imagens - de diferentes modalidades sensoriais - que o falante da língua tem sobre um determinado referente. O sinal ÁRVORE, por exemplo, representa conceptualmente árvores de diferentes tamanhos, folhas, florestas, cheiros, texturas, ou até mesmo experiências, como subir em uma árvore. "A partir dessa quantidade potencialmente vasta de informações, nós selecionamos uma imagem sensorial que irá representar todo o conceito" (TAUB, 2001, p. 45).

Outro ponto importante é que as imagens escolhidas para um mesmo conceito podem variar em línguas diferentes justamente porque podem ser estabelecidas diferentes relações culturais/contextuais com a palavra. Por exemplo, o sinal ÁRVORE em Libras seleciona uma imagem sensorial que remete a uma forma prototípica de uma árvore. Já o sinal DRZEWO (árvore) em Língua de Sinais Polonesa (PJM, Polski Język Migowy) seleciona uma imagem sensorial que remete a uma ação/evento de se cortar a árvore, conforme ilustrado na Figura 3.
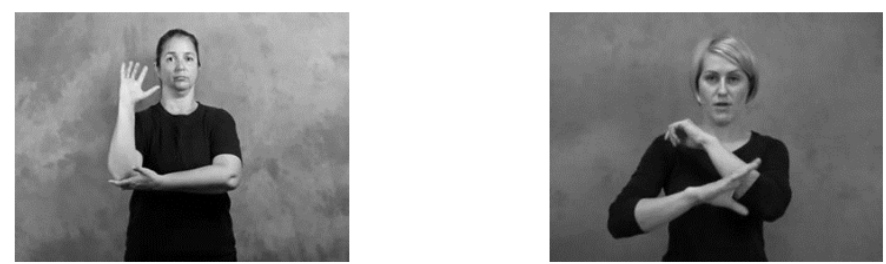

Figura 3. À esquerda, o sinal ÁRVORE em Libras e, à direita, o sinal DRZEWO (árvore) em Língua de Sinais Polonesa. Fonte: $<$ www.spreadthesign.com>.

Taub (2001, p. 45) ressalta ainda que o processo de seleção de uma imagem para representar um conceito complexo associado a ela é um exemplo de metonímia, o qual foi estudado por muitos linguistas cognitivistas, como Fauconnier (1985), Kövacecs e Radden (1998), Lakoff e Johnson (1980), entre outros. A seleção de uma imagem que se associa ao significado conceptual da palavra cria, portanto, uma relação de semelhança/iconicidade.

Taub (2001, p. 46) explica que a esquematização é o processo de destacar os detalhes importantes, de modo que a imagem esteja em um formato compatível com a língua, ainda 
que seja necessário fazer adaptações. Cada língua tem suas especificidades que podem permitir ao falante fazer certas referências e entender alguns signos linguísticos de forma específica. Então, nesse sentido, as imagens também vão sofrer alterações e adaptações nas diferentes línguas.

Ademais, é necessário levar em conta o nível de complexidade dos recursos fonéticos da língua. No caso da imagem formada pelo sinal ÁRVORE em Libras, por exemplo, os elementos visuais mais representativos são mantidos, como o solo, a haste do tronco e os galhos com as folhas. Todo o resto é desconsiderado. Isso colabora para que seja mantida apenas uma imagem mais genérica, desconsiderando elementos específicos que podem aparecer ao longo do tempo. Sendo assim, a imagem sensorial original já está esquematizada, de certo modo; devido às restrições dos nossos sistemas perceptual e cognitivo.

A codificação, segundo Taub (2001, p. 47-48), é o passo seguinte, em que é escolhida a forma física para representar cada parte e nos certificamos que esse processo de substituição preserva a estrutura geral da imagem original. O resultado é um pareamento de forma-significado que é icônico e linguístico. No caso do sinal ÁRVORE em Libras - e também em ASL -, a mão aberta pode representar a estrutura de ramificações, um antebraço na vertical pode representar o suporte alto e o antebraço na horizontal pode representar uma superfície plana.

Existem dois níveis em que as línguas fazem escolhas arbitrárias sobre o funcionamento do processo de codificação. O primeiro é sobre a escolha dos elementos icônicos específicos que devem compor a forma linguística e o segundo é sobre a escolha de quais compostos linguísticos, formados por esses elementos, devem ser mantidos como itens lexicais ou sintáticos pela língua. Essas escolhas são justamente o que diferencia o processo de codificação (mais restrito) da mímica ou imitação (livres de restrições). Na linguística cognitiva, esse processo mais restrito possui itens icônicos por esquematização imagética. Na codificação, então, cada ferramenta consiste em uma associação entre a categoria semântica e uma forma fonética, sempre preservando forma e significado. Assim, é possível ter uma forma linguística que se assemelha ao referente.

As ferramentas icônicas permitidas (pares básicos de forma-significado) para uma língua são estabelecidas convencionalmente; elas são escolhidas de maneira arbitrária a partir do conjunto de pares forma-significado possíveis. Por isso há diferenças entre representações nas línguas, ainda que a imagem seja a mesma, já que as línguas têm conjuntos próprios de ferramentas icônicas e não compartilham do mesmo inventário fonético. Por exemplo, a mesma imagem sensorial é selecionada pela Libras e pela Língua de Sinais da Letônia (LSL, latviešu zimju valoda). Contudo, a forma do sinal é distinta, uma vez que as línguas codificam de maneira diferente o sinal, considerando suas próprias propriedades fonético-fonológicas, conforme observado na Figura 4. 

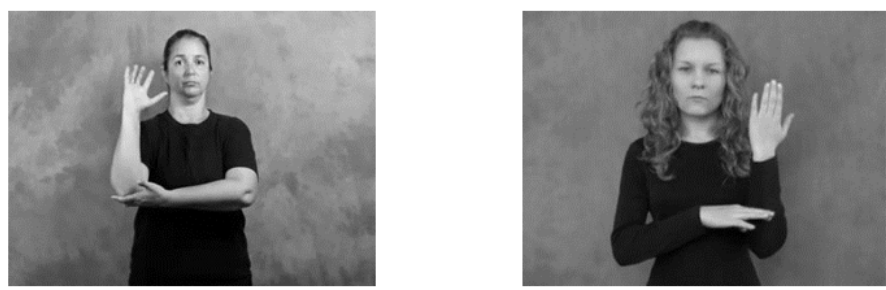

Figura 4. À esquerda, o sinal ÁRVORE em Libras e, à direita, o sinal KOKS (árvore) em Língua de Sinais da Letônia. Fonte: $<$ www.spreadthesign.com>.

Em resumo, o Modelo de Construção Analógica da lconicidade Linguística proposto por Taub (2001) nos permite identificar três processos - seleção da imagem, esquematização e codificação - que nos permite mapear a relação de analogia entre o item e seu significado.

\section{A SIMULTANEIDADE NAS LÍNGUAS DE SINAIS E O LAYERING DE INFORMAÇÕES VISUAIS NA ESTRUTURA VERBAL}

Desde os estudos seminais em linguística de línguas de sinais (STOKOE, 1960; KLIMA; BELLUGI, 1979) tem se destacado a organização simultânea das unidades mínimas que compõem essas línguas. Assim, propõe-se que os componentes fonológicos que constituem as línguas sinalizadas apresentam uma organização simultânea. Em outras palavras, todas as unidades mínimas que compõem uma mesma sílaba sinalizada são produzidas no mesmo intervalo de tempo. Assim, se considerarmos os três parâmetros fonológicos primários que formam um sinal, veremos que eles são produzidos na mesma unidade de tempo (STOKOE, 1960; FERREIRA-BRITO, 1995; QUADROS; KARNOPP, 2004).

Contudo, a simultaneidade não é uma característica restrita à estrutura fonológica nas línguas de sinais. Diferentes propostas têm indicado que a simultaneidade tem efeitos em outros componentes da gramática. Destacaremos aqui as propostas de Wilbur (2003) e de Lourenço (2018a, 2018b; LOURENÇO; WILBUR, 2018) e concentraremos nossa discussão na estrutura interna dos verbos.

Ao discutir a propriedade da simultaneidade nas línguas naturais, tanto orais quanto sinalizadas, Wilbur (2003) trabalha com o conceito de layering. 
significado, de modo a permitir que mais de uma unidade de significado linguístico (morfema) seja eficientemente transferida simultaneamente (WILBUR, 2003, p. 334). ${ }^{4}$

Apesar de presente tanto em línguas orais quanto em línguas de sinais, Wilbur (2003) argumenta que a transmissão simultânea de informações é muito mais produtiva nas línguas de sinais por elas possuírem dois articuladores principais simultâneos, que são as duas mãos, além dos articuladores não manuais, que também são usados de forma simultânea durante a sinalização. Cada um desses articuladores pode passar informações gramaticais diferentes. Nesse sentido, Figueiredo e Lourenço (2019), em concordância com Wilbur (2003), identificam na Libras quatro blocos principais de informação visual (ilustrados também na Figura 5), de modo que:

i. O sinal manual indica o item lexical;

ii. O espaço de sinalização (o local em que o sinal é localizado no espaço) pode trazer informações relacionadas a noções de referencialidade;

iii. Expressões faciais na parte superior do rosto podem transmitir informações sintáticas;

iv. Expressões faciais na parte inferior do rosto podem possuir função modificadora em nível lexical. (FIGUEIREDO E LOURENÇO, 2019, p. 80)

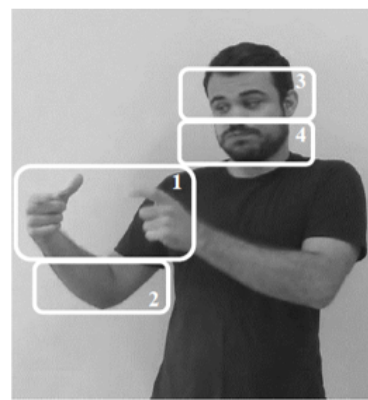

Figura 5. Layering de informações visuais na Libras. 1) sinal manual; 2) espaço de sinalização; 3) face superior; e 4) face inferior. Fonte: Figueiredo e Lourenço (2019, p. 81).

Lourenço (2018b) vai além e propõe que o layering de informações visuais também se faz presente na estrutura interna dos verbos e associa diferentes operações morfológicas a diferentes nós da estrutura fonológica interna desses elementos. A estrutura proposta pelo autor é fornecida a seguir:

4 Layering is the linguistic organizational mechanism by which multiple pieces of information can be sent simultaneously; it requires that the articulation of each piece cannot interfere with the others. Thus, layering is a conspiracy of form (articulation) and meaning to allow more than one linguistically meaningful unit of information (morpheme) to be efficiently transferred simultaneously. 


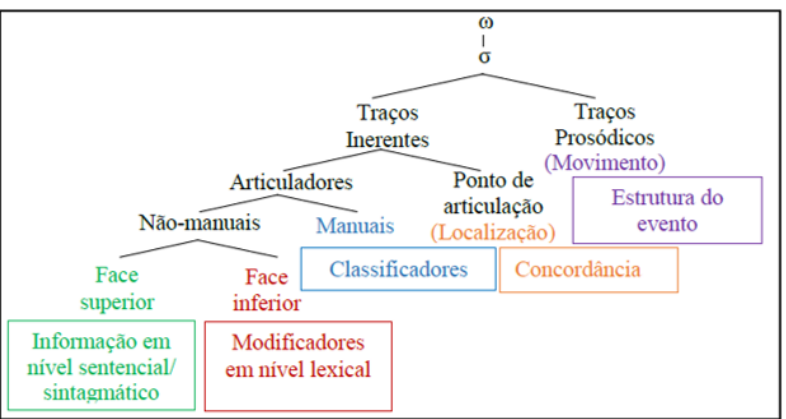

Figura 6. Layering de informações visuais na estrutura interna do verbo e respectivas operações morfológicas. Fonte: Lourenço (2018b, p. 4).

Primeiramente, é preciso diferenciar os traços inerentes e os traços prosódicos. Assumindo o Modelo Prosódico de Brentari (1998), Lourenço explica que na estrutura de Traços Prosódicos (TP)

é especificado o movimento realizado pelo sinal, assim como as mudanças de abertura das mãos. Cada nível indica a estrutura anatômica responsável por articular o movimento. Assim, os nós mais altos representam as articulações do ombro e dos braços, enquanto os nós mais baixos correspondem ao movimento das mãos e dos dedos. (LOURENÇO, 2018b, p. 3).

Já sobre a estrutura de Traços Inerentes (TI), Lourenço (2018b) diz que ela

contempla os nós Articuladores e Ponto de Articulação. O nó Articuladores, por sua vez, desmembra-se em Não-Manuais e em Manuais. Perceba que a estrutura prevê, portanto, que o sinal é especificado tanto em termos de traços manuais, que irão discriminar a forma tomada pela(s) mão(s), quanto em termos de traços não manuais, que irão descrever propriedades da cabeça e do corpo como articuladores ativos. Já no nó Ponto de Articulação, encontram-se as especificações sobre o local/região em que os articuladores se encontram no momento da realização do sinal (LOURENÇO, 2018b, p.3).

Lourenço (2018b, p.4) propõe que cada nó da estrutura fonológica pode ser alvo de uma operação morfológica específica:

i) modificações em nível sentencial/sintagmático têm como alvo as especificações de traços não-manuais, mais especificamente a região superior da face;

ii) modificações em nível lexical de caráter adverbial também alteram a estrutura de traços não-manuais, mas localizam-se na região inferior da face;

iii) construções com classificadores modificam a estrutura manual do sinal;

iv) a concordância verbal constitui-se da alteração dos traços presentes sob o nó Ponto de Articulação;

v) informações aspectuais e relacionadas à temporalidade do evento modificam a estrutura de Traços Prosódicos do sinal.

Assim, assumindo a proposta de layering de informações visuais na estrutura verbal de Lourenço (2018a, b), indagamos se é possível identificarmos a existência de mapeamentos icônicos independentes em cada slot morfológico da estrutura (interna) verbal. 
Buscaremos, portanto, associar cada mapeamento icônico a uma estrutura morfofonológica dos verbos.

Além disso, a partir da identificação de mapeamentos icônicos em cada slot morfofonológico, questionamos se seria possível a elaboração de uma escala de iconicidade a partir do número desses mapeamentos icônicos. O resultado de uma proposta como essa é termos uma escala de iconicidade que não se baseia exclusivamente nas percepções dos sinalizadores da língua, mas puramente nas estruturas morfológicas do verbo.

\section{MAPEAMENTOS ICÔNICOS NA ESTRUTURA INTERNA DOS VERBOS}

De modo a verificar a existência desses mapeamentos icônicos específicos, realizamos um levantamento de verbos em Libras e procedemos com a análise de possíveis relações analógicas presentes em cada slot morfológico proposto por Lourenço (2018a, b) e Lourenço e Wilbur (2018). A seguir detalharemos a origem dos dados, os procedimentos de análise adotados e os resultados obtidos.

\subsection{ORIGEM E SELEÇÃO DOS DADOS}

Lourenço (2018a) analisa o comportamento morfossintático, especialmente no que diz respeito aos padrões de concordância verbal, de 583 verbos da Libras. Esses verbos foram extraídos do Dicionário da Língua de Sinais do Brasil - Vol. 1, 2 e 3 (Capovilla et al, 2017). A partir das análises realizadas, Lourenço (2018a) agrupa os 583 verbos em diferentes categorias, a partir de características morfofonológicas desses itens e também a partir do tipo de concordância verbal que eles possuem.

Dentre as categorias apontadas pelo autor, destaca-se o grupo dos verbos ancorados ao corpo, que são aqueles em que o Ponto de Articulação do verbo é definido fonologicamente como sendo uma região específica do corpo do sinalizador. Lourenço (2018a) observa que esses verbos ancorados ao corpo não são capazes de marcarem morfologicamente a concordância verbal e, interessantemente, Lourenço argumenta que:

\footnotetext{
À primeira vista, a restrição para localização [concordância verbal] de verbos ancorados ao corpo parece ser de natureza fonológica. Contudo, algumas ideias da proposta de corpo-comosujeito (MEIR et a/ 2007, 2008) podem fornecer um arcabouço semântico a ser explorado, a partir da afirmação de que "o corpo do sinalizador não é somente uma localização formal para a articulação dos sinais, mas pode, a princípio, ser associado a um significado particular ou a uma função particular" (MEIR et a/ 2008). O fato de que verbos de atividade mental são realizados na/próximo da fronte ou da testa, por exemplo, não constitui apenas uma informação
} 
fonológica, mas um importante mapeamento icônico/semântico que não pode ser quebrado pela mudança de localização do verbo (LOURENÇO, 2018a, p. 189). ${ }^{5}$

A partir da observação de que verbos ancorados ao corpo possuem restrição na manifestação da concordância verbal e de que essa restrição pode ser de caráter semântico, devido à presença de um mapeamento icônico, decidimos analisar esse grupo específico de verbos identificado por Lourenço (2018a). O autor identifica que os verbos ancorados ao corpo que bloqueiam a manifestação da concordância são aqueles cujo Ponto de Articulação (PA) é cabeça, corpoo (nos termos do Modelo Prosódico de Brentari (1998) e que corresponde ao tronco) e braço, conforme apresentado na representação a seguir:

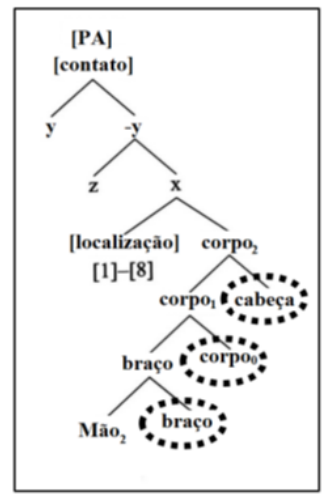

Figura 7. Estrutura do Ponto de Articulação (PA) no Modelo Prosódico. Os nós que estão marcados pela linha tracejada são aqueles que bloqueiam a concordância no verbo quando lexicalmente especificados. Fonte: Lourenço (2018b, p. 13).

Na figura a seguir, mostramos exemplos de verbos em Libras que são ancorados ao corpo, em cada uma dessas três macrorregiões, a saber: ARREPENDER, cujo PA é realizado na cabeça; SENTIR, cuja localização é no corpo/tronco; e VACINAR, cuja localização é no braço do sinalizador.

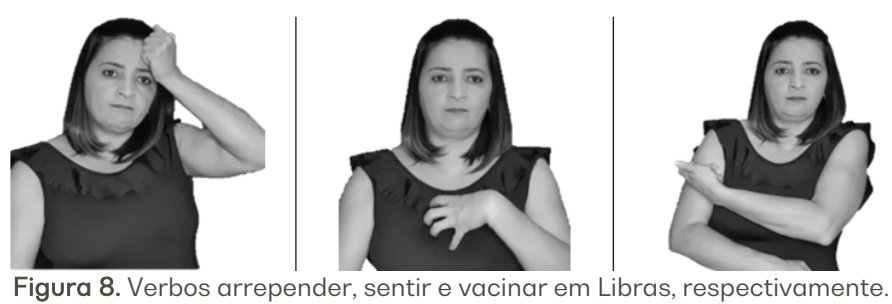

5 At first sight, the restriction for location in body-anchored verbs seems to be phonological in nature. However, some insights from the body-as-subject analysis (Meir et al, 2007, 2008) would provide an interesting semantic framework to be explored, based on the claim that "the signer's body is not merely a formal location for the articulation of signs, but may, in principle, be associated with a particular meaning or a particular function" (Meir et al, 2008). The fact that mental activity verbs are signed on/near the temple or the forehead, for instance, is not just a phonological information, but an important iconic/semantic mapping that cannot be broken by changing the location of the verb. 
Selecionamos então a lista de verbos ancorados ao corpo de Lourenço (2018a), constituída por 158 verbos. Procedemos com a análise de 153 verbos no total, já que 5 verbos foram excluídos por serem repetidos no dicionário, mas constarem sob entradas diferentes. A distribuição dos verbos analisados é fornecida na Tabela 1.

\begin{tabular}{lll}
\hline Macrorregião & Verbos & $\%$ \\
Cabeça & 103 & $67 \%$ \\
Tronco & 46 & $30 \%$ \\
Braço & 4 & $3 \%$ \\
TOTAL & 153 & \\
\hline
\end{tabular}

Tabela 1. Distribuição dos verbos ancorados ao corpo por macrorregião.

\subsection{PROCEDIMENTOS DE ANÁLISE}

Considerando a observação de Lourenço (2018a) de que os verbos ancorados ao corpo possuem algum tipo de mapeamento icônico quanto a sua localização, nossa análise passou então a verificar cada um dos cinco slots morfológicos propostos por Lourenço (2018b) e Lourenço e Wilbur (2018), a saber:

i. Marcadores de face superior;

ii. Marcadores de face inferior;

iii. Estrutura manual (configuração de mão);

iv. Localização (ponto de articulação);

v. Traços prosódicos (movimento).

Uma análise por slots nos permite: i) verificar se a observação feita por Lourenço (2018b) realmente é constatada nos verbos analisados, ou seja, de que há um mapeamento icônico na localização do sinal; ii) identificar se há mapeamentos icônicos distintos a partir de cada slot morfológico; iii) propor uma escala de iconicidade a partir do número de mapeamentos icônicos encontrados na estrutura interna do verbo.

Cada um dos 153 verbos selecionados foi analisado em sua estrutura interna, de modo a identificar possíveis relações analógicas entre forma e significado que poderiam indicar um mapeamento icônico dessas estruturas. 


\begin{tabular}{|c|c|c|c|c|c|}
\hline \multicolumn{6}{|l|}{ VERBO } \\
\hline \multicolumn{4}{|c|}{ Estrutura de Traços } & $\begin{array}{l}\text { Relação } \\
\text { analógica? }\end{array}$ & $\begin{array}{l}\text { Possível mapeamento } \\
\text { icônico }\end{array}$ \\
\hline \multirow{4}{*}{$\begin{array}{l}\text { Traços Inerentes } \\
\text { (TI) }\end{array}$} & \multirow{3}{*}{ Articuladores } & \multirow{2}{*}{$\begin{array}{l}\text { Não- } \\
\text { Manual }\end{array}$} & $\begin{array}{l}\text { i. Face } \\
\text { Superior }\end{array}$ & Sim/Não & $\begin{array}{l}\text { - Movimento de olhos; } \\
\text { - Movimento } \\
\text { sobrancelha; }\end{array}$ \\
\hline & & & ii. Face Inferior & Sim/Não & - Gestos de boca \\
\hline & & \multicolumn{2}{|c|}{ iii. Manual } & Sim/Não & $\begin{array}{l}\text { - Entidade completa; } \\
\text { - Manuseio; } \\
\text { - Extensão e superfície; } \\
\text { - Membros e partes do } \\
\text { corpo. }\end{array}$ \\
\hline & \multicolumn{3}{|l|}{ iv. Localização } & Sim/Não & $\begin{array}{l}\text { - Localização real; } \\
\text { - Localização metafórica. }\end{array}$ \\
\hline $\begin{array}{l}\text { Traços } \\
\text { Prosódicos } \\
\text { (TP) }\end{array}$ & \multicolumn{3}{|l|}{ v. Movimento } & Sim/Não & $\begin{array}{l}\text { - Translacional; } \\
\text { - Oscilatório. }\end{array}$ \\
\hline
\end{tabular}

Quadro 1. Categorias de análise baseadas nas estruturas de traços.

Apresentaremos a seguir, exemplos de relações analógicas encontradas em cada um dos slots morfofonológicos de modo a melhor explicar as categorias de análise propostas.

\subsubsection{RELAÇÕES ANALÓGICAS EM FACE SUPERIOR}

Identificamos dois tipos de relações analógicas que envolvem a face superior nos verbos analisados. A primeira envolve o movimento dos olhos. Mais especificamente, esse movimento dos olhos é análogo a um movimento real dos olhos no evento descrito pelo verbo. Por exemplo, no verbo DORMIR há um breve fechamento dos olhos do sinalizador, de maneira análoga ao fechar dos olhos em um evento do tipo 'dormir'. Outro tipo de movimento dos olhos que identificamos foi no verbo DESCONFIAR, em que há na realização do sinal um movimento de semicerrar os olhos. Esses olhos semicerrados parecem ser análogos ao evento descrito dos verbos, já que essa costuma ser uma expressão facial naturalmente associada a esse evento. Vale destacar também que, apesar de não haver contato com o rosto do sinalizador, o verbo DESCONFIAR deve obrigatoriamente ser produzido próximo ao rosto, o que nos faz analisá-lo como sendo um verbo ancorado ao corpo. Por fim, identificamos também um levantamento de sobrancelha associado ao verbo ASSUSTAR, que, em nossa análise, também consideramos que estabelece uma relação analógica à expressão facial geralmente associada ao evento descrito. Esses sinais são ilustrados na figura a seguir. 


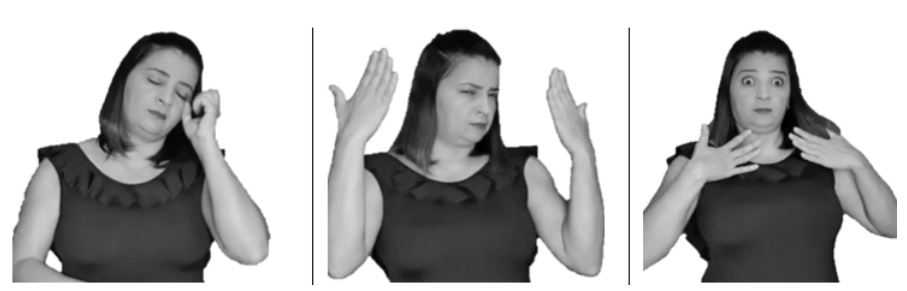

Figura 9. Verbos DORMIR, DESCONFIAR e ASSUSTAR em Libras, respectivamente.

\subsubsection{RELAÇÕES ANALÓGICAS EM FACE INFERIOR}

No que diz respeito à face inferior, identificamos em alguns verbos a presença de gestos de boca. Figueiredo e Lourenço (2019, p. 82) descrevem os gestos de boca como sendo "movimentos realizados pela boca, especificados na representação lexical do sinal e que apresentam um padrão que pode mudar durante a articulação, ou se manter constante”. É importante não confundir os gestos de boca com o mouthing que é "uma articulação silenciosa de (uma parte de) uma palavra da língua oral predominante" enquanto o sinal é realizado (PFAU; QUER, 2010, p. 3).

Em alguns verbos identificamos gestos de boca que estabelecem uma relação de analogia com o significado do evento descrito. Por exemplo, no verbo ABISMAR-SE há um gesto de boca, mais especificamente uma abertura de boca, que pode ser associada ao significado do sinal, conforme ilustrado na Figura 10.

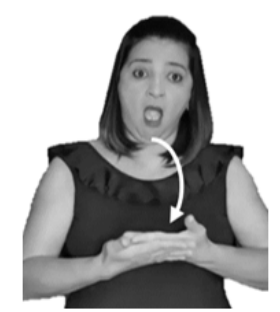

Figura 10. Verbo ABISMAR-SE em Libras.

\subsubsection{RELAÇÕES ANALÓGICAS NA ESTRUTURA MANUAL}

Conforme descrevemos anteriormente na Seção 3, a estrutura manual de um sinal pode ser alterada em construções classificadoras, a depender do referente que controla a estrutura verbal. Contudo, mesmo em itens verbais lexicais que não são considerados classificadores, podemos identificar relações analógicas na estrutura manual, ou seja, na configuração de mão do verbo.

Em nossa análise, aproveitamos de alguns rótulos utilizados na literatura para a descrição de classificadores e, assim, adotamos a tipologia proposta por EngbergPedersen (1993) para descrever os tipos de morfemas manuais. A autora propõe quatro 
categorias, a saber: i) entidade completa; ii) manuseio; iii) extensão e superfície; e iv) membros e partes do corpo.

Segundo Engberg-Pedersen (1993, p. 273), formas manuais de entidade completa denotam algo sobre uma entidade específica, ou uma quantidade não-contável (massa) de entidades tomadas como um todo ou ainda um quantitativo de entidades (contável) tomadas como um todo. No verbo PALPITAR em Libras, observamos que a representação manual - a configuração de mão - estabelece uma relação analógica com a entidade 'coração', que integra o conceito denotado pelo verbo. Nesse caso, vemos que a representação manual denota uma entidade específica. Já no caso do verbo SUAR, identificamos que a estrutura manual estabelece uma relação analógica com as entidades 'gotas de suor', que, nesse caso, trata-se de quantidade não-contável (massa) de entidades tomadas como um todo. Por fim, no verbo ver temos que a representação manual estabelece uma relação analógica com os 'olhos', tratando-se assim de quantitativo contável de entidades tomadas como um todo. Esses sinais são ilustrados na figura a seguir.

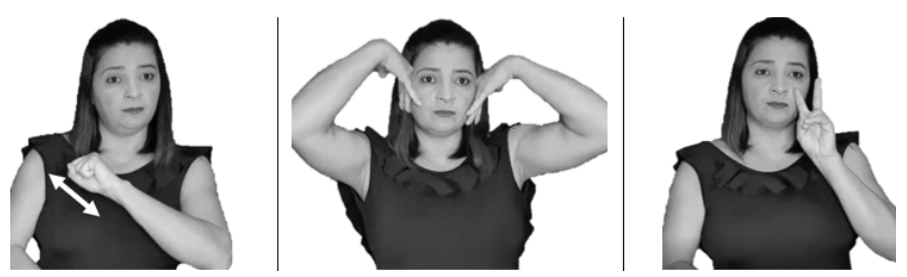

Figura 11. Verbos PALPITAR, SUAR e VER em Libras, respectivamente.

Precisamos, ainda, fazer uma observação importante acerca das relações analógicas presentes na estrutura manual. Conforme observado por um dos pareceristas deste texto, a relação de analogia entre forma e significado na estrutura manual parece ser mais opaca e, de certa forma, dependente de outras estruturas como o movimento e a locação para ser percebida. Sob essa perspectiva, a forma manual do verbo PALPITAR só parece mapear algum tipo de iconicidade se considerada a locação e o movimento do sinal. Essa observação é válida, contudo, é preciso retomarmos que a presença de mapeamento icônico não significa transparência. Assim como observado para as construções classificadoras (TANG; LI; HE, 2021), diferentemente da localização e do movimento, a estrutura manual parece ser mais convencionalizada, ou seja, menos suscetível a inovações nos mapeamentos criados. Além disso, outro paralelo interessante que observamos com os classificadores é que a estrutura manual desses verbos pode ser associada a argumentos participantes do evento descrito (BENEDICTO; BRENTARI, 2004), tais como o coração, as gotas de suor e os olhos.

É a partir dessas observações que destacamos a semelhança que esses verbos possuem com itens classificadores, já que classificadores podem ser analisados como 
sendo itens verbais cuja configuração de mão incorpora alguma propriedade saliente da entidade que participa do evento. Ademais, ao compararmos a configuração de mão de verbos como palpitar ou ver e de verbos como trabalhar (Fig. 1) e sentir (Fig. 8), vemos claramente que é possível resgatar algum tipo de mapeamento entre forma e significado naqueles, mas não nestes.

Passemos agora para o caso das formas manuais de manuseio. Na tipologia de Engberg-Pedersen (1993, p. 275), temos que elas representam:

i) um agente animado utilizando primariamente suas mãos ou membros superiores para manusear uma entidade;

ii) um agente animado movendo algo para algum lugar enquanto segura ou manuseia uma entidade;

iii) um agente animado que manuseia um instrumento qualquer além de suas mãos.

Exemplos de estruturas manuais que estabelecem relações analógicas com o evento representado podem ser encontradas nos verbos FUMAR, COBRIR-SE e ENTREVISTAR. No caso do verbo FUMAR, temos que a configuração de mão representa um agente utilizando-se de sua mão para manusear uma entidade - o cigarro. Já no caso de cobrir-se temos o segundo tipo de representação da tipologia acima, em que um agente move algo ('coberta') para algum lugar ('sobre o corpo') enquanto segura ou manuseia uma entidade ('coberta'). Já no caso do verbo ENTREVISTAR, temos a configuração de mão denotando o manuseio de um 'microfone'. Vale salientar que o verbo entrevistar não se restringe aos casos específicos de entrevistas que façam uso de microfones, mas sim, entrevistas em geral, em Libras.

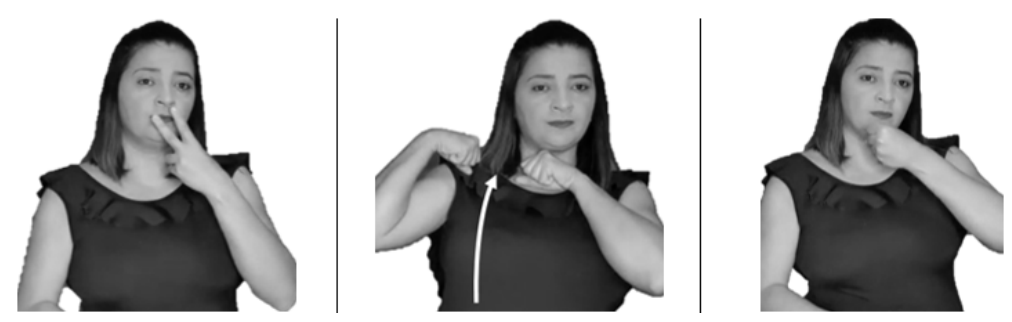

Figura 12. Verbos FUMAR, COBRIR-SE e ENTREVISTAR em Libras, respectivamente.

As formas manuais de extensão e superfície, também conhecidas como descritivas em outras tipologias, são aquelas que denotam o contorno, a forma ou a superfície de uma entidade. Podemos observar esse tipo de estrutura manual nos verbos piscar e comungar (Figura 13). Observe que nesses verbos, a forma da mão indica a forma da entidade equivalente, o 'olho' no caso do verbo piscar e a 'hóstia' no caso do verbo comungar. 

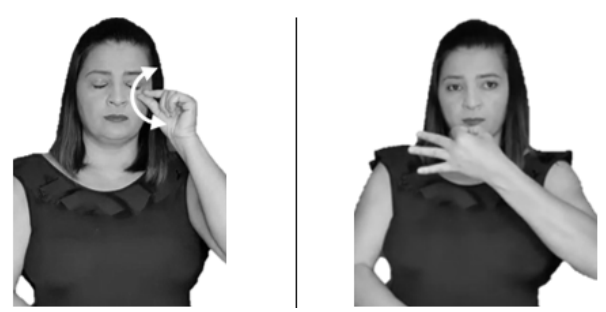

Figura 13. Verbos PISCAR e COMUNGAR em Libras, respectivamente.

Finalmente, as formas manuais de membros e parte do corpo são aquelas que denotam movimento ou o estado de partes do corpo ou de membros do agente. Encontramos esse tipo de representação nos verbos ABRAÇAR e DANÇAR (Figura 14), em que as mãos e os braços denotam propriamente as mãos e os braços do agente do evento.
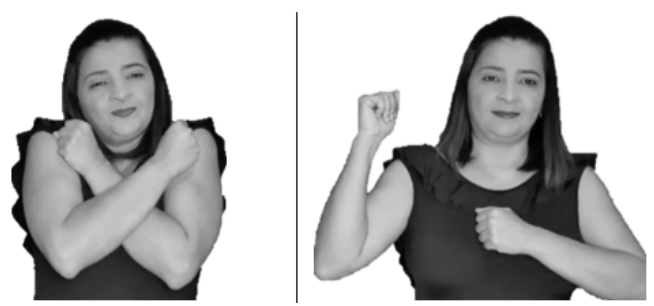

Figura 14. Verbos ABRAÇAR e DANÇAR em Libras, respectivamente.

\subsubsection{RELAÇÕES ANALÓGICAS NA LOCALIZAÇÃO}

Em nossa análise, adotamos duas classificações possíveis para as relações analógicas que envolvem a localização. Classificamos como localização rea/aqueles verbos cujo ponto de articulação coincide com a localização real no corpo do agente em que o evento ocorre ,como ocorre nos verbos CHORAR, COMER e CHEIRAR. Observe que os verbos são articulados, respectivamente, próximo ao olho, em frente à boca e em contato com o nariz, conforme ilustrado na figura a seguir.
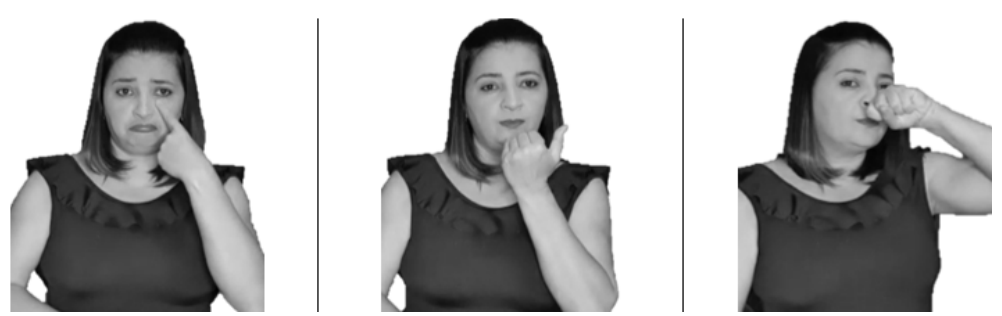

Figura 15. Verbos CHORAR, COMER e CHEIRAR em Libras, respectivamente.

Já o que classificamos como localização metafórica são aquelas localizações em que uma região do corpo é tida como correspondente ao evento descrito, mesmo que essa localização não seja exata ou precisa. Adicionalmente temos que essas relações são 
culturalmente específicas, de modo que é possível propormos estruturas metafóricas conceptuais associadas a essas localizações, à la Lakoff e Johnson (1980). Por exemplo, temos o uso da localização no peito do sinalizador para indicar verbos psicológicos - como AMAR e SENTIR na Figura 16 - e também a localização na cabeça/fronte do sinalizador para indicar verbos de atividades mentais- como APRENDER e LEMBRAR na Figura 17.

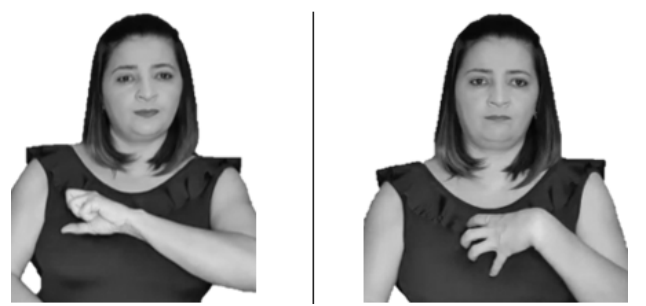

Figura 16. Verbos AMAR e SENTIR em Libras, respectivamente.

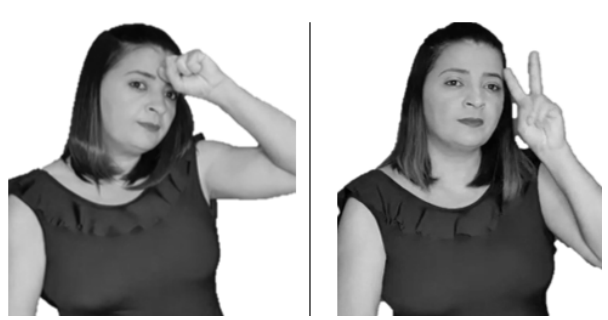

Figura 17. Verbos APRENDER e LEMBRAR em Libras, respectivamente.

\subsubsection{RELAÇÕES ANALÓGICAS NOS TRAÇOS PROSÓDICOS (MOVIMENTO)}

A última estrutura morfofonológica analisada por nós trata-se da estrutura de traços prosódicos, ou seja, o movimento do sinal. Classificamos as relações analógicas encontradas nos movimentos dos verbos de dois tipos: movimentos translacionais e movimentos oscilatórios.

Tomamos emprestado aqui os conceitos de movimento translacional e movimento oscilatório da cinemática, uma das áreas de estudo da física mecânica. Um movimento é considerado translacional quando ele resulta em uma mudança de locação. Já o movimento oscilatório é considerado um movimento, muitas vezes repetitivo, que oscila em torno da mesma localização.

Dentre os verbos analisados, podemos citar como exemplos de relação analógica que denota um tipo de movimento translacional os verbos COBRIR-SE e NASCER. Observe que em ambos os exemplos, o movimento realizado pelo verbo é análogo ao movimento dos participantes do evento. Assim, o movimento do verbo COBRIR-SE é análogo à mudança de posição do tema 'coberta/cobertor'. Já o movimento do verbo NASCER é análogo à mudança de posição do bebê em um evento de parto. Os verbos são ilustrados na figura a seguir. 


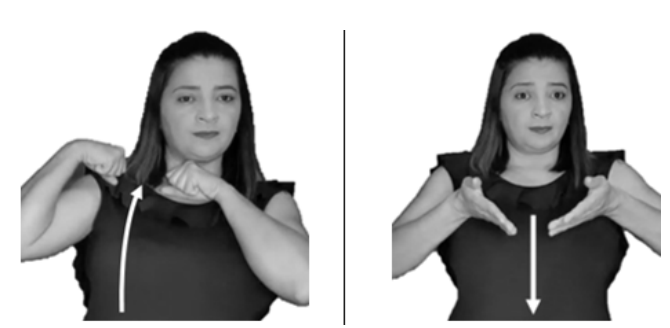

Figura 18. Verbos COBRIR-SE e NASCER em Libras, respectivamente.

Já o movimento oscilatório pode ser observado em verbos cujo movimento fonológico cria uma relação analógica com algum tipo de dinamicidade presente no evento, sem, contudo, indicar mudança de posição ou locação. Nesse caso, podemos citar os verbos PALPITAR e PISCAR, em que o movimento do verbo é icônico ao movimento do evento, sem que haja mudança de localização ou posição.
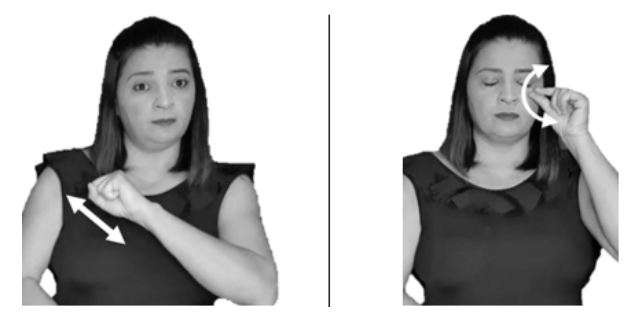

Figura 19. Verbos PALPITAR e PISCAR em Libras, respectivamente.

Apresentadas as categorias de análise adotadas, passemos agora a discutir os resultados com o levantamento dos verbos ancorados ao corpo.

\subsection{ANÁLISE DOS MAPEAMENTOS ICÔNICOS PRESENTES NOS VERBOS ANCORADOS AO CORPO}

A partir das categorias propostas, analisamos a estrutura interna de 153 verbos ancorados ao corpo, listados em Lourenço (2018a) e extraídos do Dicionário da Língua de Sinais do Brasil (Capovilla et al 2017). Assim, buscamos identificar possíveis relações analógicas entre a forma e o significado desses verbos, decompondo-os nos cinco slots morfofonológicos propostos por Lourenço (2018b) e Lourenço e Wilbur (2018).

Antes de procedermos com uma análise mais específica dos números de possíveis mapeamentos icônicos encontrados na estrutura interna dos verbos, começaremos por apontar algumas observações interessantes que podem ser realizadas a partir dos dados compilados. Se somarmos a quantidade de verbos que apresentam cada um dos cinco mapeamentos possíveis, constatamos pelo menos dois comportamentos interessantes. Os dados consolidados são apresentados a seguir. 


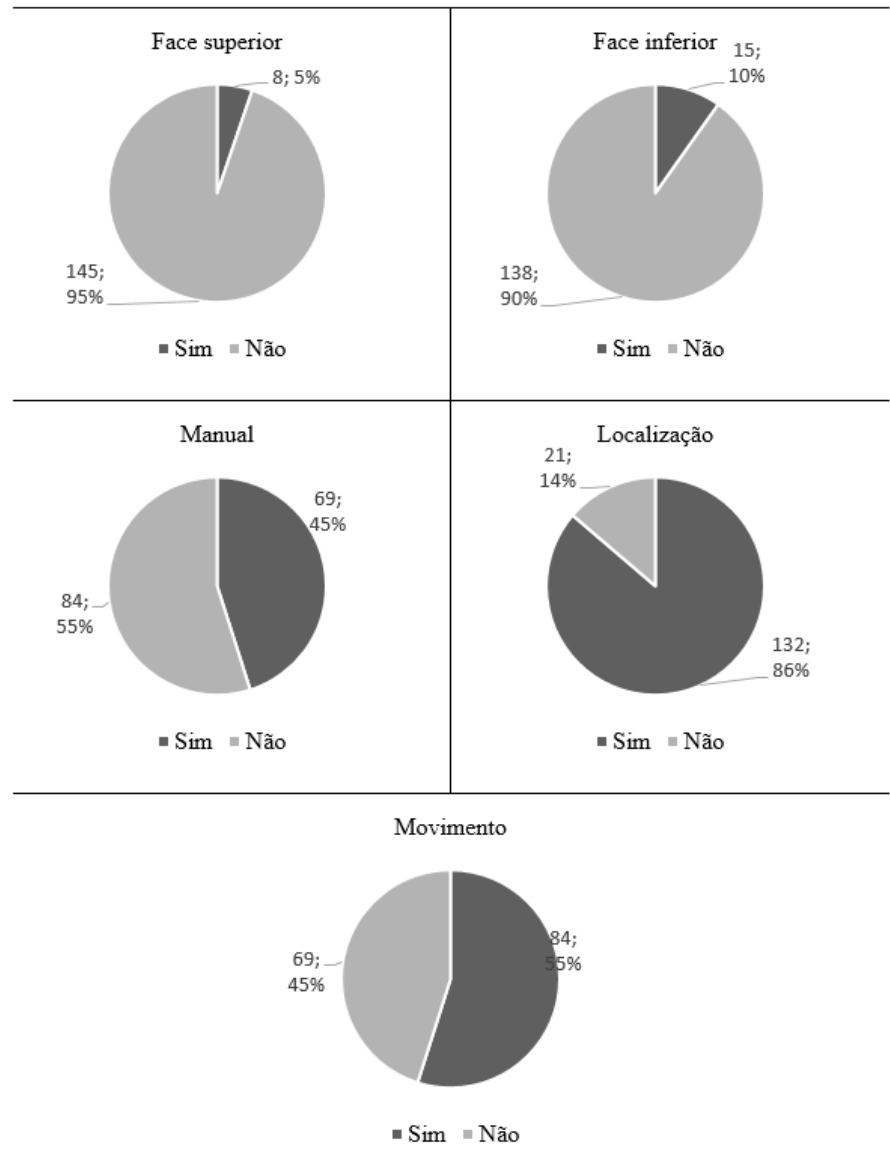

Gráfico 1. Compilado de mapeamentos icônicos por slotmorfofonológico.

A partir dos gráficos acima, podemos observar que as estruturas morfofonológica que menos apresentam relações analógicas são justamente as não manuais (face superior e face inferior). Conforme descrito na Seção 3, a face superior é responsável por marcações relacionadas às estruturas sintáticas, enquanto a face inferior pode marcar modificações em nível lexical, mais especificamente no caso dos verbos, modificações do tipo adverbiais. Uma hipótese que pode ser levantada para explicar a baixa ocorrência de mapeamentos icônicos nas estruturas não manuais é a de que estas são bastante recrutadas para a transmissão de informações gramaticais e que, portanto, é compreensível que essas estruturas sejam desprivilegiadas nos processos de formação de itens lexicais icônicos, já que mapeamentos icônicos poderiam comprometer possíveis operações morfológicas subsequentes, uma vez considerado o princípio de preservação da estrutura. Assim, uma vez que não há uma predominância de mapeamentos icônicos em face superior e inferior, essas estruturas ficam disponíveis para possíveis modificações gramaticais que se façam necessárias na estrutura da língua. 
Outra observação interessante é a de que, dentre os verbos analisados, a estrutura que mais apresenta mapeamentos icônicos é justamente a localização. Em 86\% dos verbos analisados foi possível identificarmos alguma relação analógica entre forma e significado. Esse resultado é, certamente, consequência do fato de termos analisado apenas verbos ancorados ao corpo. Além disso, o comportamento icônico desses verbos no que diz respeito à localização parece corroborar o argumento de Lourenço (2018a) de que a localização desses verbos codifica também informações semânticas e que "o fato de que verbos de atividade mental são realizados na/próximo da fronte ou da testa, por exemplo, não constitui apenas uma informação fonológica, mas um importante mapeamento icônico/semântico que não pode ser quebrado pela mudança de localização do verbo" (LOURENÇO, 2018a, p. 189). ${ }^{6}$

Por fim, podemos apontar ainda para o fato de que mapeamentos icônicos, apesar de serem bastante produtivos em Libras, devido à questão da modalidade visuoespacial da língua, não parecem ser predominantes na estrutura dos verbos, se considerarmos separadamente cada slot morfológico. Isso nos ajuda também a entender melhor qual a extensão da iconicidade na formação dos sinais, uma vez que podemos encontrar um mapeamento icônico em uma subestrutura específica e não encontrarmos nenhuma relação analógica entre forma e significado nas demais. Isso nos faz levantar a questão de que se um sinal apresenta um mapeamento icônico em apenas um slot morfofonológico e não apresenta nenhuma relação de iconicidade nas demais, podemos reduzir esse item a simplesmente um "sinal icônico"? Iconicidade, portanto, não pode ser analisada como um fenômeno binário (sim/não).

\section{QUANTOS MAPEAMENTOS ICÔNICOS CABEM EM UM VERBO?}

Após a análise dos dados compilados, passemos a discutir a quantidade de mapeamentos icônicos que cada verbo pode ter em sua estrutura. O gráfico a seguir demonstra a quantidade de verbos que não apresenta nenhum mapeamento icônico em sua estrutura e a quantidade de verbos que apresenta 1, 2, 3, 4 ou 5 mapeamentos.

6 The fact that mental activity verbs are signed on/near the temple or the forehead, for instance, is not just a phonological information, but an important iconic/semantic mapping that cannot be broken by changing the location of the verb. 


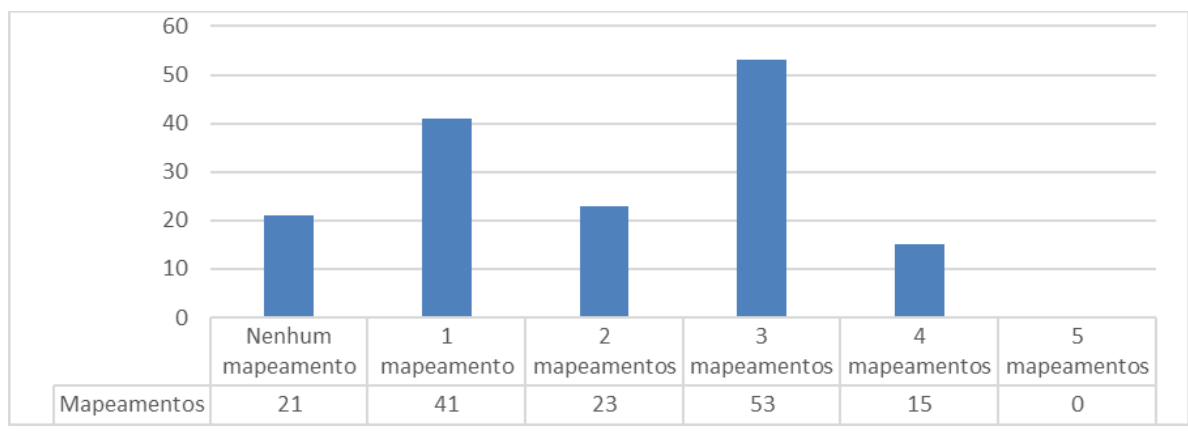

Gráfico 2. Quantitativo de verbos por quantidade de mapeamentos icônicos na estrutura interna.

Conforme mostrado no gráfico acima, não há nenhum verbo em nossos dados que apresente cinco mapeamentos icônicos em sua estrutura interna. Ou seja, não há nenhum item analisado que seja completamente icônico, acionando todos os slots morfofonológico do verbo.

Discutiremos agora os dados dos verbos que não apresentam nenhum mapeamento icônico em sua estrutura e também os que possuem um, dois, três ou quatro mapeamentos identificados.

\subsection{VERBOS SEM NENHUM MAPEAMENTO ICÔNICO}

Identificamos 21 verbos em que não foi possível constatar nenhuma relação analógica entre forma e significado em nenhum slot morfofonológico. Um exemplo é o verbo ADOTAR, apresentado na Figura 20. Novamente, isso revela que a iconicidade não está presente em todos os sinais da Libras, conforme já discutido amplamente na literatura linguística. Línguas sinalizadas não são estritamente icônicas (KLIMA; BELLUGI, 1979; STOKOE, 1960).

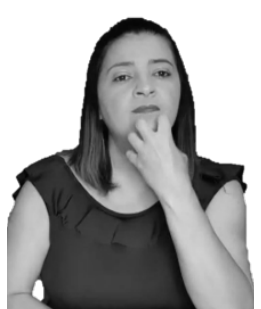

Figura 20. Verbo ADOTAR em Libras.

\subsection{VERBOS COM UM MAPEAMENTO ICÔNICO}

41 verbos apresentaram apenas um único mapeamento icônico em sua estrutura interna. Interessantemente todos esses verbos apresentaram relações analógicas de forma e significado no componente localização. Isso já era esperado, uma vez que nosso critério de 
seleção foi justamente verbos ancorados ao corpo. Exemplos são os verbos SABER e PECAR, apresentados na Figura 21.
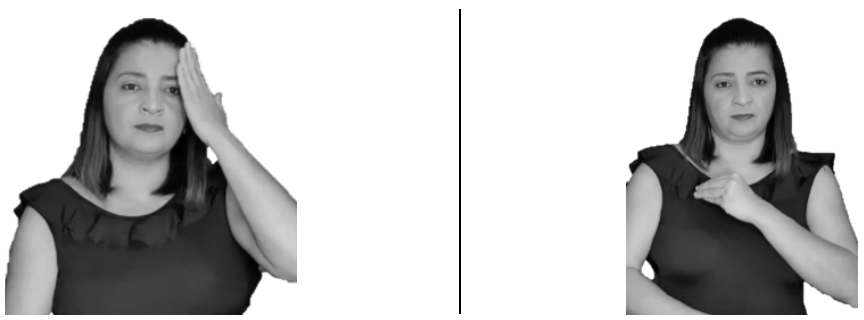

Figura 21. Verbos SABER e PECAR em Libras, respectivamente.

\subsection{VERBOS COM DOIS MAPEAMENTOS ICÔNICOS}

23 verbos apresentaram dois mapeamentos icônicos em sua estrutura. Novamente, a estrutura localização está presente em todos eles como estrutura icônica, o que já era esperado. Além disso, há ocorrências de mapeamentos em todos os demais slots - face superior, face inferior, manual e movimento), conforme observado no Gráfico 3.

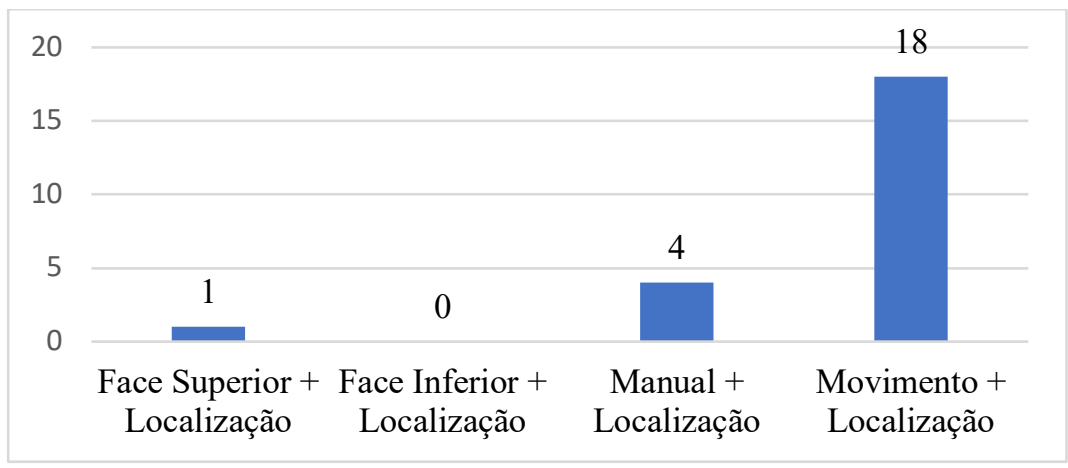

Gráfico 3. Distribuição dos verbos que possuem dois mapeamentos icônicos.

Observamos também que a incidência de mapeamentos na face superior é pequena, além de não termos encontrado nenhuma ocorrência na face inferior, provavelmente pelos motivos já discutidos anteriormente. Vale apontar também que, dentre as combinações possíveis, a estrutura de movimento aparece em 18 dos 23 verbos que apresentam dois mapeamentos icônicos. Isso pode apontar que o movimento dos verbos pode se mostrar bastante propício a codificar relações de iconicidade.? Exemplos de cada uma das combinações observadas no Gráfico 3 são apresentados na figura a seguir. 

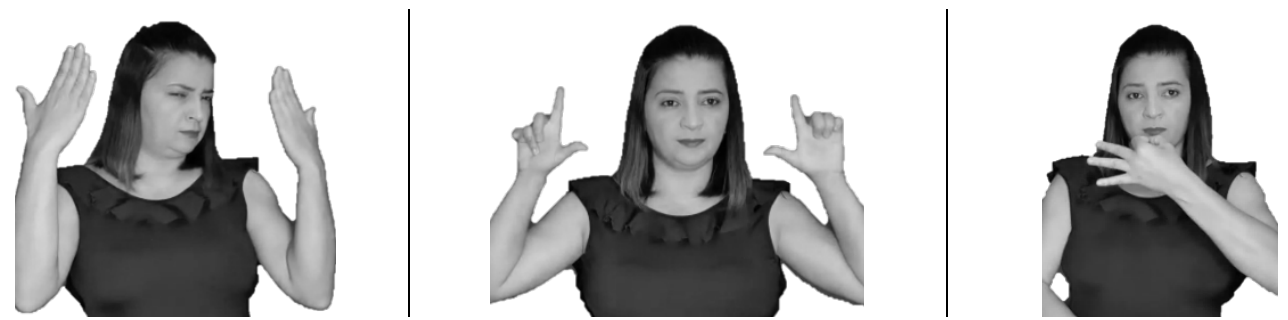

Figura 22. Verbos DESCONFIAR (face superior + localização), APARECER_TV (manual + localização) e OPINAR (movimento + localização) em Libras, respectivamente.

\subsection{VERBOS COM TRÊS MAPEAMENTOS ICÔNICOS}

53 verbos apresentaram mapeamentos icônicos em três estruturas internas. Como consequência da observação anterior de que os componentes não manuais apresentam pouco mapeamento icônico, uma vez que possuem função gramatical importante na gramática da língua, observa-se que 48 desses verbos apresentam relações analógicas entre forma e significado nos componentes Manual, Localização e Movimento. Vale também lembrar que na literatura esses são os chamados parâmetros primários (FERREIRA-BRITO, 1995) e que, portanto, parecem ser mais explorados em um tipo de mapeamento que pressupõe um tipo de preservação da estrutura. Exemplos são fornecidos a seguir:

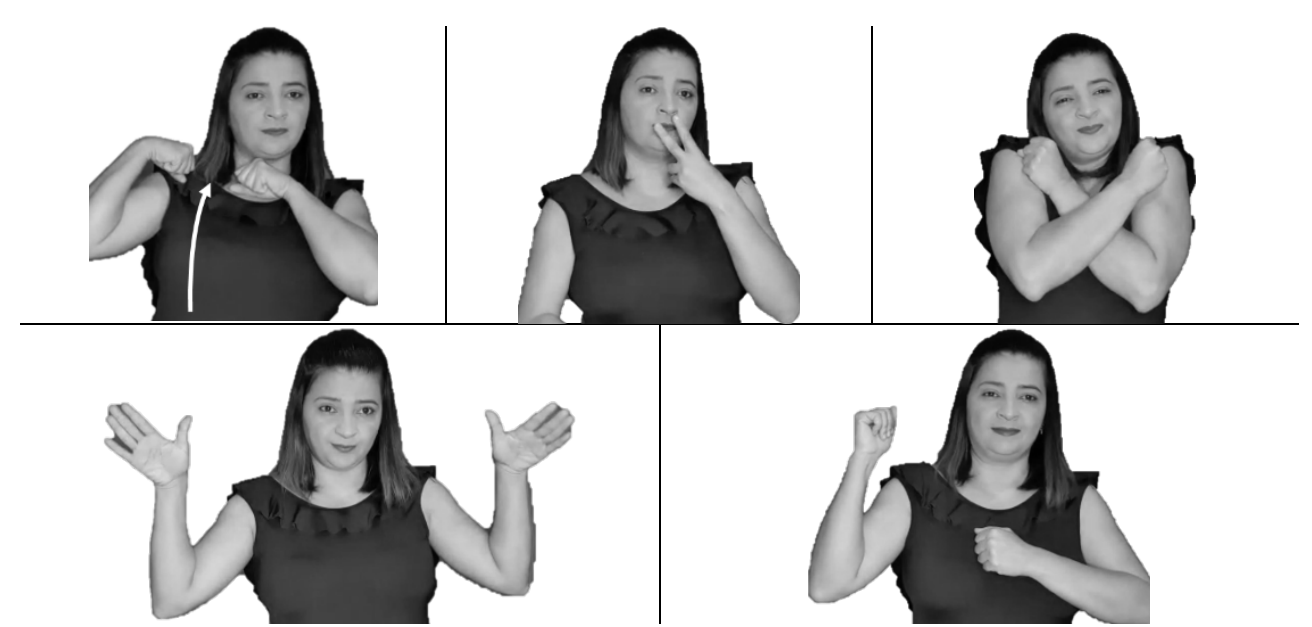

Figura 23. Verbos COBRIR-SE, FUMAR, ABRAÇAR, VOAR e DANÇAR em Libras, respectivamente. Todos apresentam mapeamentos icônicos nas estruturas Manual, Localização e Movimento.

Outra observação importante é que os sinais que apresentam três mapeamentos icônicos em sua estrutura fonológica primária também parecem ter uma forte influência de substrato gestual. Percebe-se, portanto, que quanto maior o número de mapeamentos icônicos presentes na estrutura do verbo, mais parece haver influência de gestualidade em sua criação. Essa observação alinha-se às discussões sobre gestos como fonte de 
lexicalização de sinais nas línguas sinalizadas (Petitto 1983, 1990; Singleton et al, 1995; Senghas et al, 2000). Esta, certamente, é uma questão interessante a ser abordada em pesquisas futuras.

\subsection{VERBOS COM QUATRO MAPEAMENTOS ICÔNICOS}

Apenas 15 dos 153 verbos analisados apresentam quatro mapeamentos icônicos. Todos apresentam relações analógicas nas estruturas Manual, Localização e Movimento. Além dessas três estruturas, 4 verbos apresentam também mapeamento icônico na face superior (exemplos fornecidos na Figura 24) e 11 verbos apresentam mapeamento icônico na face inferior (exemplos fornecidos na Figura 25).
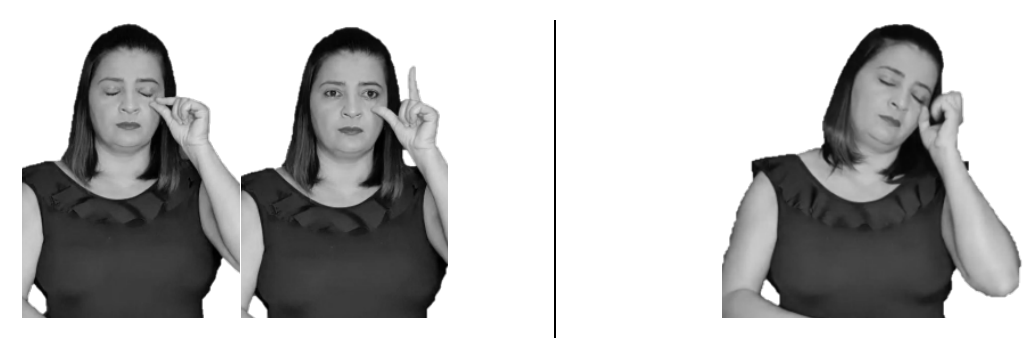

Figura 24. Verbos ACORDAR e DORMIR em Libras, respectivamente.
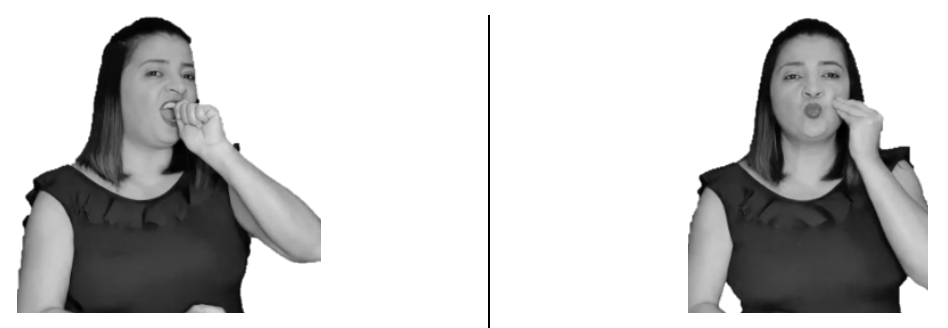

Figura 25. Verbos ACORDAR e BEIJAR em Libras, respectivamente.

Assim, como observado nos verbos com três mapeamentos, os verbos com quatro mapeamentos também parecem possuir um componente ou uma origem gestual forte, o que certamente merece ser investigado em pesquisas futuras.

\subsection{UMA POSSÍVEL ESCALA DE ICONICIDADE VERBAL A PARTIR DOS MAPEAMENTOS NA ESTRUTURA INTERNA DOS VERBOS}

Até aqui, discutimos a estrutura interna dos verbos ancorados ao corpo, de modo a verificar a presença de relações analógicas entre forma e significado em cada um dos slots morfofonológicos propostos por Lourenço (2018b) e Lourenço e Wilbur (2018). Vimos que sim, é possível identificar a existência de mapeamentos icônicos independentes em cada 
slot. Além disso, os nossos dados corroboram com a observação feita por Lourenço (2018a) de que nos verbos ancorados ao corpo, a localização tem, conforme constatado na maioria dos verbos analisados por nós, uma função semântica importante, não sendo apenas de natureza fonológica.

Como consequência natural da proposta de mapeamentos icônicos independentes na estrutura interna dos verbos, propomos uma escala de iconicidade baseada apenas na estrutura morfofonológica do item lexical, conforme ilustrado na Figura 26.

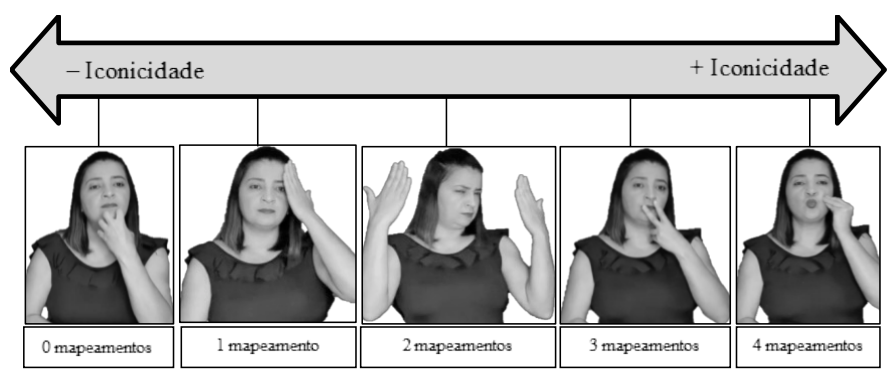

Figura 26. Escola de iconicidade baseada na estrutura morfofonológica do verbo

A partir da proposta dessa escala, assumimos que a iconicidade não é uma característica binária (sim/não), mas sim gradual, conforme vem sendo proposto na literatura (KLIMA; BELLUGI, 1979; EMMOREY, 2014; inter alia). Salientamos, por fim, que a escala proposta acima deve ainda ser submetida a testagens e validação, o que pretendemos fazer em pesquisas futuras.

\section{CONSIDERAÇÕES FINAIS}

Neste artigo argumentamos que é possível identificar mapeamentos icônicos independentes em cada "camada" de informação visual da estrutura interna dos verbos em Libras. Em específico, analisamos os verbos ancorados ao corpo e que possuem como localização a cabeça, o tronco ou o braço, seguindo a lista de verbos encontrada em Lourenço (2018a). Adotando o Modelo de Construção Analógica da Iconicidade Linguística (TAUB, 2001), propusemos a existência de mapeamentos icônicos independentes na estrutura morfológica do item verbal e que cada slot morfológico pode codificar relações icônicas entre forma e significado. Além disso, indicamos ser possível estabelecer o grau de iconicidade que item verbal possui a partir da quantidade de mapeamentos icônicos presentes em sua estrutura interna, de modo a construirmos uma escala de iconicidade que leva em consideração a estrutura morfofonológica do item lexical. 
A proposta teórica aqui delineada deriva novos questionamentos que precisam ser melhor investigados. Primeiramente, é preciso ampliarmos nossa análise para os verbos que não são ancorados ao corpo. Além disso, a proposta de escala de iconicidade precisa ser testada e validada. Por fim, vale questionarmos quais são as possíveis restrições impostas pelos mapeamentos icônicos a processos morfológicos que poderiam incidir sobre a categoria verbal.

\section{REFERÊNCIAS}

ARONOFF, M.; MEIR, I.; SANDLER, W. The paradox of sign language morphology. Language, v. 81, p. 301-344, 2005.

BENEDICTO, E.; BRENTARI, D. Where did all the arguments go?: Argument-changing properties of classifiers in ASL. Natural Language and Linguistic Theory, v. 22, n. 4, p. 743-810, 2004.

BRENTARI, D. A prosodic model of sign language phonology. Cambridge MA: MIT Press, 1998.

BRENTARI, D. Sign Language Phonology. Cambridge University Press, 2019.

CAPOVILLA, F. C.; RAPHAEL, W. D.; TEMOTEO, J. G.; MARTINS, A. C. Dicionário da Língua de Sinais do Brasil. São Paulo: EDUSP, 2017.

EMMOREY, K. Iconicity as structure mapping. Philosophical Transactions of the Royal Society B: Biological Sciences 369, 2014.

ENGBERG-PEDERSEN, E. Space in Danish Sign Language: The Semantics and Morphosyntax of the Use of Space in a Visual Language. International Studies on Sign Language Research and Communication of the Deaf, v. 19. Hamburg: Signum Press, 1993.

FAUCONNIER, G. Mental Spaces: Aspects of Meaning Construction in Natural Languages. Cambridge: Cambridge University Press, 1985.

FERREIRA-BRITO, L. Por uma gramática de Língua de Sinais. Rio de Janeiro: Tempo Brasileiro, 1995.

FIGUEIREDO, L. M. B.; LOURENÇO, G. O movimento de sobrancelhas como marcador de domínios sintáticos na Língua Brasileira de Sinais. Revista da Anpoll, v. 1, n. 48, p. 78-102, 2019.

GROSSO, B. Iconicity and Arbitrariness in Italian Sign Language: An Experimental Study. Padua: University of Padua, 1993.

HAIMAN, J. The Iconicity of Grammar: Isomorphism and Motivation. Language, v. 56, n. 3, p. 515-540, set. 1980.

HOEMANN, H. The transparency of meaning of Sign Language gestures. Sign Language Studies, n. 7, p. 151-161, 1975.

KLIMA, E.; BELLUGI, U. The Signs of Language, Cambridge, MA.: Harvard University Press, 1979.

KÖVACECS, Z.; RADDEN, G. Metonymy: Developing a Cognitive Linguistic View. Cognitive Linguistics, v. 9, n. 1, p. $37-$ $77,1998$.

LAKOFF, G.; JOHNSON, M. Metáforas da vida cotidiana. Campinas: Mercado de Cetras, 2002 [1980].

LOURENÇO, G. Verb agreement in Brazilian Sign Language: Morphophonology, Syntax \& Semantics. 2018. $320 \mathrm{f}$. Tese (Doutorado em Linguística Teórica e Descritiva) - Faculdade de Letras, Universidade Federal de Minas Gerais, Belo Horizonte, 2018a. 
LOURENÇO, G. Layering de informações visuais e a estrutura morfofonológica dos verbos em Libras. In: CONGRESSO NACIONAL DE PESQUISAS EM LINGUÍSTICA E LIBRAS, 2, 2018, Florianópolis. Anais.... Florianópolis, 2018b.

LOURENÇO, G.; WILBUR, R. B. Are plain verbs really plain?: Co-localization as the agreement marker in sign languages. FEAST. v. 2. Venice: Universitat Pompeu Fabra, p. 68-81, 2018.

MEIR, I. Iconicity and metaphor: Constraints on metaphorical extension of iconic forms Language. Language, v. 8, n.4, p. 865- 986, 2010 .

MEIR, I.; TKACHMAN, O. Iconicity. In: ARONOFF, M. (ed.). Oxford Research Encyclopedia of Linguistics. [s. I.]: Oxford University Press, mar. 2018

ORTEGA, G.; SÜMER, B.; ÖZYÜREK, A. Type of iconicity matters in the vocabulary development of signing children. Dev. Psychol., n. 53, p. 89-99, 2017.

PFAU, R.; QUER, J. Nonmanuals: their grammatical and prosodic roles. In: BRENTARI, D. (ed.). Sign Languages, [s. I.]: Cambridge University Press, 2010, p. 381-402.

QUADROS, R. M. de; KARNOPP, L. Língua de sinais brasileira:estudos lingüísticos. Porto Alegre: ArtMed, 2004.

SAUSSURE, F. Curso de Linguística Geral. 12ª ed. São Paulo: Cultrix, [1915].

SEVCIKOVA SEHYR, Z.; EMMOREY, K. The perceived mapping between form and meaning in American Sign Language depends on linguistic knowledge and taks: evidence from iconicity and transparency judgments. Language and Cognition, v. 11, n. 2, p. 208-234, jun. 2019.

SHINTEL, H.; NUSBAUM, H. Analog acoustic expression in speech. Journal of Memory and Language, v. 55, n. 2, p. 167-177, ago. 2006

STOKOE, W. Sign Language Structure: An Outline of the Visual communication Systems of the American Deaf. Studies in Linguistics, Occasional paper 8. Silver Spring, MD: Linstok, 1960.

TANG, G.; LI, J.; HE, J. Classifiers: theoretical perspectives. In: QUER, J.; PFAU; R. HERRMANN; A. (org). The Routledge Handbook of Theoretical and Experimental Sign Language Research. London: Routledge, 2021.

TAUB, S. F. Language from the body: Iconicity and metaphor in American Sign Language. Cambridge: Cambridge University Press, 2001.

WAUGH, L. R. Degrees of Iconicity in the Lexicon. Journal of Pragmatics, n. 22, p. 71-81, 1994.

WILBUR, Ronnie B. "Modality and the Structure of Language: sign languages versus signed systems". In: MASCHARK, Marc; SPENCER, Patricia Elizabeth (org). Oxford handbook of deaf studies, language, and education. Nova York: Oxford University Press, 2003. 